\title{
Bulk and Position-Specific Isotope Geochemistry of Natural Gases from the Late Cretaceous Eagle Ford Shale, South Texas
}

Heng Zhao ${ }^{1,2}$, Changjie Liu ${ }^{2}$, Toti E. Larson ${ }^{3}$, Gregory P. McGovern ${ }^{4}$, Juske Horita ${ }^{2}$

${ }^{1}$ Jiangsu Design Institute of Geology for Mineral Resources, Key Laboratory of Shale Gas, CNACG, Key Laboratory of Mineral Resources in Coal Measures, CNACG, Xuzhou 221006, Jiangsu, China

${ }^{2}$ Department of Geosciences, Texas Tech University, TX, 79409, USA

${ }^{3}$ Bureau of Economic Geology, The University of Texas at Austin, TX, 78713, USA

${ }^{4}$ Department of Chemistry and Physics, West Texas A\&M University, TX, 79016, USA

A dataset of bulk and position-specific isotope compositions of shale gases from the Late Cretaceous Eagle Ford Shale, south Texas is reported. The chemical and bulk isotopic compositions of the seven samples in this study and those available from the literature show that across the play, produced natural gas from the Eagle Ford Shale preserves a wide range of gas compositions (wetness, $\sim 5$ to $>90 \%$ ) and $\delta^{13} \mathrm{C}$ values of $\mathrm{C}_{1}-\mathrm{C}_{3}$. The depth profiles of the isotopic compositions suggest that the western region of the Eagle Ford Shale deposit had experienced as much as 700-800 m of uplift-erosion or gas migration. The timing of and lost-gas fractions by gas expulsion events very likely affected their gas compositions and bulk isotope compositions. Some deep $(>3000-3500 \mathrm{~m})$, matured $\left(\% \mathrm{R}_{0}>1.5\right)$ gases with heavy $\delta^{13} \mathrm{C}\left(\mathrm{C}_{1}-\mathrm{C}_{3}\right)$ values indicate significant loss $(>50 \%)$ of the early-stage gases. For the position-specific isotope deviations of propane, the $\Delta \mathrm{C}_{2-1}$ values of the five samples show small decrease with well depths, while the $\Delta \mathrm{H}_{2-1}$ values have a general increasing trend. Although some samples fall very close to the equilibrium model trajectories with reasonable calculated temperatures $\left(138-148{ }^{\circ} \mathrm{C}\right)$, the position-specific isotope compositions of propane from the Eagle Ford Shale gases are likely results of thermal cracking of various organic molecules within the source rocks, which have different activation energy for cracking and non-statistical distributions of $\mathrm{C} / \mathrm{H}$ isotope within them. 